Association for Information Systems

AIS Electronic Library (AISeL)

\title{
Recombining layers of digital technology: How users create and capture value
}

Axel Hund

University of Bamberg, Chair of Information Systems and Services, Bamberg, Germany

Viktoria Diel

University of Bamberg, Chair of Information Systems and Services, Bamberg, Germany

Heinz-Theo Wagner

Neu-Ulm University of Applied Sciences, Ulm, Germany

Follow this and additional works at: https://aisel.aisnet.org/wi2021

Hund, Axel; Diel, Viktoria; and Wagner, Heinz-Theo, "Recombining layers of digital technology: How users create and capture value" (2021). Wirtschaftsinformatik 2021 Proceedings. 8.

https://aisel.aisnet.org/wi2021/JDigitalInnovation16/Track16/8

This material is brought to you by the Wirtschaftsinformatik at AIS Electronic Library (AISeL). It has been accepted for inclusion in Wirtschaftsinformatik 2021 Proceedings by an authorized administrator of AIS Electronic Library (AISeL). For more information, please contact elibrary@aisnet.org. 


\title{
Recombining layers of digital technology: How users create and capture value
}

\author{
Axel Hund ${ }^{1}$, Viktoria Diel ${ }^{1}$, Heinz-Theo Wagner $^{2}$ \\ ${ }^{1}$ University of Bamberg, Chair of Information Systems and Services, Bamberg, Germany \\ \{axel.hund\}@uni-bamberg.de \\ ${ }^{2}$ Neu-Ulm University of Applied Sciences\{heinz-theo.wagner\}@hnu.de
}

\begin{abstract}
Recombination is central to the creation of innovation. Since digital innovation is product and use agnostic, not only producers and firms can carry out recombination, but users themselves can select and recombine different digital resources. We investigate why users select and recombine digital resources from different layers (content, service, network, device) of the layered modular architecture in a personal context. Our results allow us to make three key contributions: (1) We underscore the importance to distinguish between intra-layer and inter-layer recombination and uncover different reasons to carry out intra- or inter-layer recombination. (2) We show that the network layer appears to be invisible to users when recombining digital resources in a personal context. (3) We outline recommendations and research questions for future research, based on our findings.
\end{abstract}

Keywords: digital innovation, recombination, use recombination, design recombination

\section{Introduction}

The concept of recombination is central to innovation research since the seminal writings of Schumpeter: "To produce means to combine materials and forces within our reach [...] To produce other things [...] means to combine these materials and forces differently" [1, p.65]. Since then, the perspective that innovation is created by combining already existing materials and forces in new ways is enduring across disciplines (e.g., [2, 3]). By applying the concept of combination and recombination to different environments, research has found that not only the physical components of a product can be recombined to generate innovation, but also knowledge (e.g., [4]) and organizational units (e.g., [5]).

Drawing on the recombination perspective, extant research notes that digital innovation comes about by recombining digital and physical components and exhibits a new form of architecture distinct form traditional non-digital products. Digital innovation is now characterized by the layered modular architecture, which "[...] extends the modular architecture of physical products by incorporating four loosely coupled layers of devices, networks, services, and contents created by digital technology" [6, p.724].

16th International Conference on Wirtschaftsinformatik,

March 2021, Essen, Germany 
Within and across these four different layers resources can be recombined in unforeseen ways leading to digital innovation [6,7]. Moreover, this recombination can be performed by users. Until recently, recombination was implicitly considered to be only carried out by producers (e.g., [8-11]) since recombining different components in order to produce value required product-specific expertise and an overview of the product design [6]. In that respect, Henfridsson et al. [11] argue that traditional innovation research focuses almost exclusively on recombination carried out by producers, yet the malleability of digital resources enables users to perform recombination themselves. This is possible, because digital resources, which are "entities that serve as building blocks in the creation and capture of value from information" [11, p.90] are highly malleable and allow flexible recombination with other digital resources across different layers. Therefore, it is necessary to distinguish between design recombination and use recombination to better understand how recombination can lead to digital innovation. Design recombination is carried out by producers who define how a certain set of digital resources is connected in order to create a value offering for users. Use recombination, on the other hand, is performed by the users of such value offerings and describes the activity of recombining different parts of an offering with parts of another offering [11].

However, extant studies' exclusive focus on design recombination undercuts insights from the cocreation literature that show "how value is created in use by many actors, suggesting that digital innovation is a collaborative effort of integrating resources" [11, p.91]. Until now, we have very limited insights into what prompts users to select different digital resources and recombine them across and within the four different layers of device, network, services, and contents. Thus, we put forward the following research questions:

RQ1: Which specific digital resources from the four layers of content, service, network, and device are selected by users and why?

RQ2: How and why do users recombine digital resources within and across the four layers of devices, networks, services, and contents?

To answer the research question, we conducted 21 exploratory interviews in which we asked about the digital resources selected by the respondents. We then categorized these digital resources along the four layers of device, network, service, and content to determine how and why users select and recombine digital resources from different layers. In the next section, we review the relevant literature before describing our methodology. We then present our findings and discuss their theoretical and practical implications. We conclude with an outlook on future research and a short conclusion.

\section{Related Literature}

"Recombination is at the heart of innovation" [11, p.89]. This is also true for digital innovation, which is defined as the process of creating new products by recombining physical and digital components in novel ways [6]. Doing so leads to new market offerings and business processes, which already transformed entire industries [12] and initiated the rapid decline of previous market leaders such as Kodak [13]. By recom- 
bining physical components with digital components, previously analog products become digitized and acquire the properties of digital technologies such as reprogrammability [14], and editability [15]. These properties are central to digital innovation and require firms to organize within innovation networks $[16,17]$ and change the way innovation is managed $[12,18]$. Furthermore, while purely physical products typically have a modular architecture, recombining digital and physical components leads to a layered modular architecture, which consists out of four loosely coupled layers (content, service, network, device) [6]. These four layers lead to fluid product boundaries and allow the recombination of components across different layers for different purposes. The fluid product boundaries make the components in a layered modular architecture product agnostic since they can be recombined with other components independently of a specific design hierarchy and the envisioned final product [6].

While research already distinguishes between different types of recombination that focus on either tangible components, organizational structures or knowledge [19], recombination is predominantly regarded as an activity carried out by the producer-side (e.g., firms) to create value offerings to consumers and users [e.g., 8, 20]. Henfridsson et al. [11] call recombination carried out by producers design recombination and note that design recombination is only one side of the coin. The other side is recombination carried out by users while using different value offerings, which is called use recombination. Importantly, users can be individuals, firms or even algorithms [11]. By combining and recombining parts of various value offerings in use, users make use of the agnostic nature of digital resources $[6,21]$. Doing so, users contribute to the "increasingly amorphous agency as well as vaguely determined initial outcomes, resulting from a continuous flow of augmenting, expanding, and integrating new digital technologies into infrastructure and broader ecosystems" [22, p.5]. Hence, the traditional distinction between central and peripheral stakeholders is increasingly obsolete, since players take different roles in different networks. "Instead there are many formal and informal networks, with relatively little overlap, each for its own different and often temporary purpose" [23, p.17].

Following this line of thought, Henfridsson et al. [11] argue that the unit of analyses must shift from products and components to the notion of digital resources. Digital resources, which enable capturing value from information and serve as building blocks for digital innovation, can manifest on each of the four layers (content, service, network, device). This shift towards digital resources also underlines the malleability and agnosticism associated with the layered modular architecture, which enables users themselves to recombine different value offerings from firms in unforeseen ways [11]. While users have more influence, it is only by considering design recombination and use recombination together we obtain a full picture about recombination [24].

Figure 1 illustrates how for each layer, there exists a value space, which is a network of interlinked digital resources, which are created and dissolved by various actors for differing purposes. Each digital resource "(1) belongs to a specific value space, (2) hosts the potential to simultaneously be part of multiple value paths, and (3) is typically product-agnostic" [11, p.92]. Producers conduct design recombination by connecting digital resources to create value paths, which serve as value offering to users, whereas users carry out use recombination by selecting a specific digital resource from such 
value offerings and connecting them to digital resources from other value offerings. By connecting digital resources in unforeseen ways across and within layers, users create individual value connections [11].

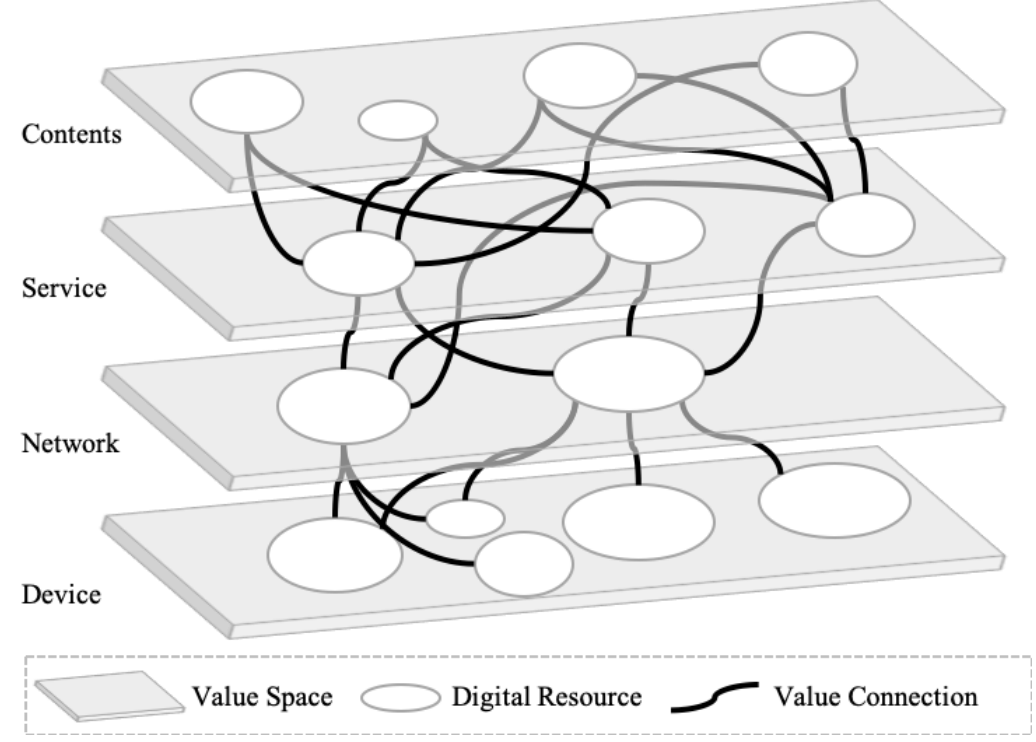

Figure 1. Value Spaces, Digital Resources, Value Connections (based on Henfridsson et al. [11])

\section{Method}

Qualitative, explorative research methods are perfectly suited for open research questions as they are able to provide initial information about a topic and to create a basic understanding of the research subject [25]. While recombination itself is a well-researched subject across various fields (e.g., [1, 4, 6]), use recombination is a newly established area in the field of recombination and innovation research [11]. Thus, we chose an explorative research approach to examine which specific digital resources from the four layers of content, service, network, and device are selected by users and why? Furthermore, we want to understand how and why users recombine digital resources within and across the four layers of devices, networks, services, and contents to create digital innovation. To identify suitable interview partners, we established various rules such as the interest in digital services and devices and the regular use of digital services and devices as selection criteria. Furthermore, to gain better insights into use recombination in a personal context, we focused on users with different educational and professional backgrounds that recombine digital resources in a predominantly personal context. In total 21 interviews were conducted, as listed in table 1.

The interviews were conducted on site between August and October 2019 using a semi-structured interview guide and were based on the following structure: First, the participants were asked about their attitudes towards digital resources and their expertise in dealing with them. Then they were asked which digital resources they use and 
how often they use them. Following up, the focus shifted towards the reasons and motivation for selecting and recombining various resources. Afterwards, the participants were asked to describe how exactly they go about selecting, combining and recombining different digital resources. The interviews were recorded with the consent of the interviewees and subsequently transcribed.

Table 1. Overview Interview Partners

\begin{tabular}{clll}
\hline ID & \multicolumn{1}{c}{$\begin{array}{c}\text { Educational } \\
\text { Level }\end{array}$} & \multicolumn{1}{c}{$\begin{array}{c}\text { Field of } \\
\text { Education and Training }\end{array}$} & \multicolumn{1}{c}{$\begin{array}{c}\text { Current } \\
\text { Occupation }\end{array}$} \\
\hline IP01 & Bachelor & Business Administration & Student \\
IP02 & Bachelor & Business Administration & Student \\
IP03 & A-Levels & Mechanical Engineering & Student \\
IP04 & Bachelor & Mechanical Engineering & Student \\
IP05 & Master & Business Education & Teacher \\
IP06 & Bachelor & Health Care Management & Assistance to Management \\
IP07 & Professional Training & Bike Mechanic & Paramedic \\
IP08 & Professional Training & Office Clerk & Administrative Employee \\
IP09 & Master & Electrical Engineering & Research Assistant \\
IP10 & Master & Business Administration & Project Engineer \\
IP11 & Master & Business Administration & Institutional Sales Manager \\
IPI2 & Bachelor & Robotics & Student \\
IP13 & Master & Innovation Management & Digital Innovation Manager \\
IP14 & Bachelor & Educational Sciences & Student \\
IPI5 & Professional Training & Electrical Engineering & Electrical Engineer \\
IPI6 & Master & Business Administration & Human Ressource Manager \\
IP17 & Master & Physics & Research Assistant \\
IP18 & Doctorate & Mechanical Engineering & Speaker Business IT \\
IP19 & Professional Training & Industrial Clerk & Commercial Clerk \\
IP20 & Master & Business Administration & Senior Associate Consulting \\
IP21 & Professional Training & Wholesale Merchant & Commercial Clerk \\
\hline & & &
\end{tabular}

Data analysis was carried out after transcription according to the guidelines for qualitative content analysis by Mayring [25]. To do so, we defined clear research questions and then identified a framework in the literature to guide our data analysis. The layered modular architecture of digital technology, which is central to the field of digital innovation research in general and use recombination in specific $[6,11]$, was chosen. Following best practices in the literature $[25,26]$, we deductively coded each interview according to our coding guidelines. Table 2 provides an overview of the characteristics of each layer and the respective coding rule. After categorizing relevant codings along the four layers of the layered modular architecture, we inductively coded within each category, searching for patterns and emerging subcategories. Any unclear codings were discussed among the authors until an agreement was reached. 
Table 2. Coding Guidelines based on Yoo et al. [6] and Henfridsson et al. [11]

\begin{tabular}{|c|c|c|}
\hline Layer & Layer Characteristic & Coding Rule \\
\hline Content & $\begin{array}{l}\text { Definition: The content layer in- } \\
\text { cludes digital data. } \\
\text { Example: Maps, music, video, } \\
\text { pictures }\end{array}$ & $\begin{array}{l}\text { Statements about information of any kind } \\
\text { in a digital format, which can be stored, } \\
\text { shared, watched, read, etc. }\end{array}$ \\
\hline Service & $\begin{array}{l}\text { Definition: The services layer is } \\
\text { software based and consists of } \\
\text { functional applications enabling } \\
\text { the interaction with contents. } \\
\text { Example: Social media Applica- } \\
\text { tions, smart lightning }\end{array}$ & $\begin{array}{l}\text { Statements about any application that is } \\
\text { selected by the user for its specific func- } \\
\text { tionality and/or enables the processing of } \\
\text { contents. }\end{array}$ \\
\hline Network & $\begin{array}{l}\text { Definition: The network layer } \\
\text { consists of logical transmission } \\
\text { software and the physical } \\
\text { transport resources. } \\
\text { Example: Transmitters, network } \\
\text { standards }\end{array}$ & $\begin{array}{l}\text { Statements about the selection of digital } \\
\text { and non-digital resources that enable the } \\
\text { transmission of signals. }\end{array}$ \\
\hline Device & $\begin{array}{l}\text { Definition: The device layer con- } \\
\text { tains hardware and software re- } \\
\text { sources for storing and processing } \\
\text { Example: Computer, operating } \\
\text { system }\end{array}$ & $\begin{array}{l}\text { Statements about any kind of hardware } \\
\text { and/or the software needed to use the hard- } \\
\text { ware. }\end{array}$ \\
\hline
\end{tabular}

\section{Analysis Part 1: Digital Resource Categories and Reasons for Selection}

To answer our first research question "Which specific digital resources from the four layers of content, service, network, and device are selected by users and why?" we now present our results regarding specific digital resources. We first show which digital resources our interview partners mentioned and then go on to highlight reason for users to select a specific digital resource.

\subsection{Digital Resources Selected by Users - An Overview}

For the content layer we coded statements about information in any kind of digital format, which can be stored, shared, watched, read etc. Examples are contents such as music, podcasts, books, videos and maps. During our analysis three subcategories emerged, which help structuring the identified digital resources in the content layer even further. The subcategories are audible, visual, and written and describe the nature of the content. 
Table 3. Types of Digital Resources

\begin{tabular}{|c|c|c|}
\hline Layer & Subcategory & Examples \\
\hline \multirow{3}{*}{$\begin{array}{l}\overrightarrow{\tilde{0}} \\
\stackrel{\overrightarrow{0}}{0}\end{array}$} & Audible & Podcast, music, voice message \\
\hline & Visual & Pictures, video, video telephony, series, movies, maps \\
\hline & Written & Books, notes, links, written messages \\
\hline \multirow{11}{*}{ 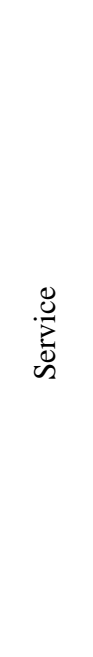 } & Messaging & $\begin{array}{l}\text { WhatsApp, Skype, e-mail client (e.g., Outlook), Telegram, } \\
\text { iMessage, Facebook Messenger }\end{array}$ \\
\hline & Streaming & $\begin{array}{l}\text { Netflix, Amazon Prime Video, Spotify, Apple Music, } \\
\text { YouTube }\end{array}$ \\
\hline & Navigation & Google Maps, Apple Maps, Open Street Maps \\
\hline & Socializing & Facebook, Snapchat, Xing, LinkedIn \\
\hline & Storage & OneDrive, Dropbox, Google Drive, iCloud, Own Cloud \\
\hline & Voice Assistance & Siri, Google Assistant, Alexa \\
\hline & Payment & PayPal, Apple Pay, Google Pay \\
\hline & Online Shopping & $\begin{array}{l}\text { AirBnB, Booking.com, Amazon, H\&M, Zalando, eBay, } \\
\text { Lieferando, Check24 }\end{array}$ \\
\hline & Smart Home & Smart lightening, smart heating, smart shutters \\
\hline & Browser & Opera, Internet Explorer, Google Chrome \\
\hline & Mobility & DB-Navigator, Uber, car sharing \\
\hline \multirow{2}{*}{$\begin{array}{l}\stackrel{\circlearrowright}{d} \\
\stackrel{\Delta}{0}\end{array}$} & Immobile & Beamer, printer, PlayStation, smart TV \\
\hline & Mobile & $\begin{array}{l}\text { Smart board, smartphone, tablet, laptop, e-book reader, smart } \\
\text { watch, Bluetooth box, headphones, e-scooter, car }\end{array}$ \\
\hline
\end{tabular}

The service layer is defined as software based functional applications, which enable the interaction with contents. Examples include services such as WhatsApp, Netflix, Spotify etc. Each of the identified services enables users to access and interact with content and the service layer is also the most frequently mentioned layer within our data set. Analyzing the way, the interviewees referred to a respective service allows inductively deriving subcategories based on the functionality the mentioned applications offer. By following this logic, a total of eleven subcategories emerged, which are categorized by what kind of service they provide. For example, applications such as Netflix and Spotify, which offer the service of streaming series or music, are both categorized as "Streaming" services. While they enable access to and interaction with different types of contents (Spotify / audible content, Netflix / visual content) they nonetheless provide the same type of service (streaming). Similarly, "Messaging" includes services, which enable access to and interaction with any kind of digital messages, even if the nature of the content differs significantly such as in the case of e-mail providers and Skype.

One of the key findings in this step of analysis was the absence of any mentions of the network layer. The network layer is about digital and non-digital resources that en- 
able the transfer of signals or how Henfridsson et al. [11, p.94] put it: the "logical transmission software and the physical transport resources". While the network layer plays an important role by providing network standards (e.g., TCP/IP) [6], it appears that users do not consider different networks. This might hold interesting implications for design recombination, which we will address in the discussion.

The device layer is defined as hard- or software which is needed to be able to use digitalized hardware. Examples include laptops, beamers, smartphones etc. During the analysis two subcategories emerged, which allow to distinguish between "immobile" and "mobile" devices. Immobile devices can only be used at the location they were installed at whereas mobile devices can be used at any place. Table 3 provides an overview of the identified digital resources.

\subsection{Reasons for Selecting Digital Resources}

After the identification of different digital resources across the layers of content, service and device, we now turn to the reasons for selecting a specific digital resource. Besides the obvious reasons for selecting a digital resource (such as perceived usefulness and perceived ease of use [e.g., 27]), we discover that integration, compatibility, and network effects are particularly important in the context of digital resources.

Integration is about tight linkings between different digital resources. By tightly integrating different digital resources with each other, it is possible to ensure better synchronization between certain digital resources, which can lead to a better performance and less problems arising when combining digital resources that are intended to be linked with each other. This can help saving time, which was mentioned frequently and appears to be a general reason for the selection of digital resources. Or how IP13 put it: "[...] the inherent promise of technology is to save time". Similarly, a tight integration can also increase the overall experienced convenience. "I am very open-minded, [...] I am actually often looking for things that simplify life in general" (IP17). Convenience plays an important role when deciding between similar value offerings from different companies. For example, the level of integration between different digital resources offered by a company plays an important role. "[I] am a dedicated apple user, so I really like the fact that it's all integrated, synchronized and yes, it makes my life easier in many ways" (IP02). Similarly, payment services, which are tightly integrated with a specific device also help saving time and increase convenience in daily life. "I use payment services such as ApplePay, because it is much, much more convenient to pay with it, it is faster at the checkout, you briefly hold your smartphone up to the front of the device for the cards and you don't have to enter a pin, you confirm with your fingerprint or with FaceID. It is simply much faster and more convenient than paying by card or cash" (IP04). Time saving and convenience are the most common reasons for selecting voice assistance. "Very, very open, because I think it simply makes everyday life easier, perhaps to save time or in situations where you shouldn't be distracted by typing something somewhere that can be done with a voice assistant." (IP07) However, data protection also plays a role in connection with voice assistance. The factors convenience and time-saving are important when choosing a navigation service. "Both 
Apple [maps] and Google [maps] [...], [...], to avoid traffic jam, so I usually let both navigate in parallel to see where I can save time, who wants to be in a traffic jam, right?" (IP07). While a tight integration of certain digital resources can increase convenience and simplify life, it typically reduces the overall compatibility with other digital resources, which is another frequently mentioned reason for selecting a digital resource.

Compatibility with other digital resources is another major reasons for selecting a digital resource. In this context, storage services are noteworthy, with several respondents saying that they select a storage solution, because it is compatible with their own devices or with other users' operating systems. This is summed up in the statement of IP04: "iCloud for example is much more compatible with Apple devices than Dropbox, so I use iCloud for internal sharing and Google Drive is of course much more compatible with Windows products and Android products, so my friends probably use it and to share documents with them as easy as possible I use it as well". Additionally, the availability of materials independently of a device and also the provision of free storage capacity by a storage service is an advantage for IPs. IP02 stated: "meanwhile I like the cloud services very much, because you can easily access them from all kinds of devices" and IP04 pointed out: "in the past I used Dropbox a lot, because I had free storage there and my friends also used it". In addition, storage services are being selected for the improved collaboration, e.g. in group work. "With Dropbox you had the possibility [...] to edit things online, but also to exchange with other people, [...] which was extremely practical especially for the university, also for presentations or other group projects" (IP11). Further, the number of users a service has was mentioned to be an important factor for selection, particularly for social and messenger services (e.g., IP07). Here, compatibility with other digital resources influences how many users can access and use a specific service. For example, IP07 states "So, WhatsApp [...] started, because there are just so many people". Similarly, social recommendations play an important role, yet users can only follow recommendations from their social circle if the respective digital resource is compatible with the digital resources they are using.

Network effects. In addition, the number of users a service has was frequently mentioned as an important factor for selection, particularly in the case of social and messenger services. Some services are almost exclusively selected because they already have a high number of users and are, therefore, more useful for other users. For example, IP07 states: "Well, WhatsApp [...] started because there are just so many people". But other services whose value proposition is not about social contacts or the promise that many other people will use the service also benefit from higher user numbers, as social recommendations play an important role. For example, IP03 states: "I came to Spotify or Netflix mainly through friends who used it before and recommended it to me". 


\section{Analysis Part 2: How and Why Do Users Recombine Different Digital Resources Within and Across Layers?}

Building upon the identified categories of digital resources and why users select them, we now turn to our second research question: How and why do users recombine digital resources within and across the four layers of devices, networks, services, and contents? In total, we identify five different paths that users take to recombine digital resources. One key insight is the importance of distinguishing between recombining digital resources within the same layer, which we term intra-layer recombination and recombining digital resources across different layers, which we term inter-layer recombination. Furthermore, we identify different paths that users take to carry out intra-layer recombination (Path 1-4) and inter-layer recombination (Path 5). Figure 2 depicts an overview of the different paths of recombination in use.
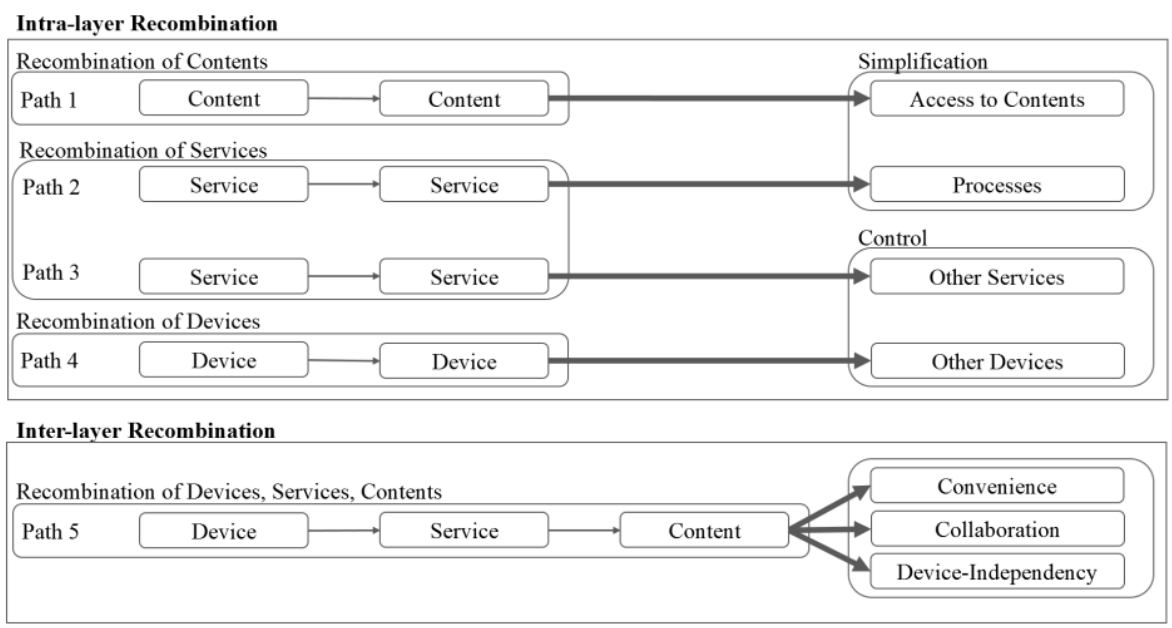

Figure 2. Different Paths of Use Recombination

\subsection{Intra-layer Recombination}

Path 1: Content Layer. The first path for use recombination takes places on the content layer. Users typically recombine different digital resources at the content level to facilitate access by embedding a piece of content such as a link or file in a message or other document to make the content available to others. For example, IP05 describes an intra-layer recombination on the content level by integrating links on exercise sheets for students, which facilitates accessing the content.

Path 2: Service Layer. The second path for use recombination takes place on the service layer. Users typically recombine digital resources at the service level to simplify a process and benefit from several services simultaneously. For example, the process of 
buying something online is oftentimes carried out by using multiple services simultaneously. Typically, the service of an online shopping service is combined with a payment service. IP03 stated for instance: "Well, [...] the most common example is actually shopping over the smartphone, e.g. at Amazon or Zalando, I always pick out things that I would like to have and then I am transferred from the shopping cart to e.g. Paypal and can pay my purchase directly with the Paypal app." In this context IP05 mentioned that the payment process is significantly simplified by the recombination of the services. Hence, intra-layer recombination within the content or service layer is carried out to simplify a process or simplify access to content.

Path 3: Service Layer. The second path within the service layer, is initiated by a voice assistant. Voice assistants appear to have a specific role in use recombination since they are typically used to control various other digital resources. Examples from the interviews include among others the use of the voice assistant to set a timer "I use voice assistance to set a timer" (IP09), to add things to note applications, to start streaming services "I'll tell Siri to open up Spotify" (IP06), to control smart home applications as smart lightening or smart heating "I can control my smart home products via voice assistance" (IP03) or to start the navigation in navigation services. It was noticeable that voice assistance was always used to control the other service. Hence, intra-layer recombination on the service layer that includes the use of a voice assistant is carried out to control other services.

Path 4: Device Layer. The fourth path for use recombination takes place on the device layer. The intra-layer recombination on the device layer is carried to control other devices - similar to the reason stated for Path 3. For example, on the device layer users state that the combination of mobile devices with other mobile devices (e.g., smartphone and Bluetooth box) is mentioned since it allows to conveniently add more functionalities. Furthermore, they recombine mobile devices such as a smartphone with immobile devices such as smart TVs, to facilitate remote control. For example, IP10 states: "I can control my TV with my smartphone" (IP10). Hence, intra-layer recombination within the device layer is carried out by recombining mobile and immobile devices to enable remote control.

\subsection{Inter-layer Recombination}

Path 5: Device, Service, and Content Layer. The fifth path for use recombination takes place across the device, service, and content layer. Path 5 depicts how users select one or several digital resources on the device layer to use one or several digital resource on the service layer, which then enables access to one or several digital resources on the content layer. Typically, Path 5 leads to more convenience when using specific offerings. IP04 provides an example of Path 5 which starts by connecting the smartphone (device) with a car (device) via a car communication application (service) and goes on with accessing a navigation service (service) by using voice assistance (service) of the smartphone and the map (content). The interview partner highlights how recombining 
various digital resources from different layers increases the convenience of the navigating process immensely. IP09 complements this path by adding streaming services (service) and the music (content) they provide. This again contributes to the convenience the recombination of devices, services and contents offers to the user. Thus, interlayer recombination across the device, service, and content layer can include one or several digital resources from each layer and is carried out to increase the overall convenience of using specific offerings.

Furthermore, users recombine digital resources across the device, service, and content layer to enable collaboration and become independent from specific physical devices. For example, IP06 describes recombining a laptop (device) with a document (content), which is then uploaded into a cloud (service) folder to be shared via a link (content) with other people by sending the link in a message (content) via a messenger (service) or to be downloaded on a different device (e.g. tablet or smartphone). Doing so facilitates collaborating with multiple people (IP06) and also decreases dependency on a specific physical device by accessing documents "from the laptop I share via iCloud with my iPad and with my smartphone so that I can use it on all devices" (IP04). Hence, inter-layer recombination across the device, service, and content layer can facilitate collaboration and reduce the dependency on a specific device.

\section{Discussion and Conclusion}

To better understand the interplay of various actors pursuing different purposes, we set out to examine how and why users select and recombine digital resources from the layered modular architecture [6].

As stated in the introduction, our research questions are:

RQ1: Which specific digital resources from the four layers of content, service, network, and device are selected by users and why?

RQ2: How and why do users recombine digital resources within and across the four layers of devices, networks, services, and contents to create digital innovation?

Regarding RQ1, we found that users only select digital resources from the content, service, and device layer, while not considering the network layer. Additionally, we identify 16 subcategories across the three layers of content (3 subcategories), service (11 subcategories), and device (2 subcategories). Moreover, our results show that users select digital resources depending on the level of integration and compatibility, as well as network effects. While a tight integration of digital resources can increase convenience and simplify life, it reduces the overall compatibility with other digital resources. These contradicting reasons to select a digital resource underscore the oftentimes paradoxical nature of digital innovation $[28,29]$ and highlight that digital innovation also creates paradoxical circumstances for individuals in a non-professional context.

Regarding RQ2, we identify five different paths that users take to recombine different digital resources. More specifically, we show the importance to distinguish between intra-layer and inter-layer recombination [11] since there are different reasons for carrying out intra- or inter-layer recombination. While intra-layer recombination aims mainly at facilitation (e.g., access to contents/processes) and controlling other services 
or devices, inter-layer recombination appears to enable collaboration and increasing independency from specific physical devices. Moreover, our results demonstrate that use recombination in a non-professional context is oftentimes not primarily focused on the creation of novelty as is the case in design recombination (e.g., $[6,30]$ ) but provides a way for users to generate an individual value path that addresses a personal problem and, thereby, create and capture value [11].

Before discussing the implications of our findings, we want to highlight some limitations that have to be considered. Methodologically, our research is limited since we only included users in a non-professional context from German-speaking countries in the data collection, i.e. the results of this study allow only limited conclusions to be drawn about the behavior pattern during recombination and the reasons behind the use of digital innovations by people from other cultures or in a professional context. Furthermore, particularly young participants ( $<20$ years) and persons older than 39 years were not included in the study, which is why no statement can be made about their user behavior. Beyond this, a distortion of the results of the study can be assumed due to the subjective selection of the experts who were interviewed on the topic and it cannot be assumed that these experts represent the entire population. Moreover, the answers cannot be checked for completeness or accuracy, which is why it must be trusted that the respondents answered the questions honestly and completely. However, Helfferich [31] notes that if someone takes part in an interview, it can be assumed that this person will not lie openly.

Despite these limitations, our findings allow us to make some suggestions for practitioners: producers who want to expand their user base need to consider the reasons behind a user's choice, as users actively weigh the pros and cons of different digital resources. In particular, the degree of integration and compatibility that each digital resource exhibits appear to be deciding factors for users. Considering these factors will enable producers to actively promote more valuable links with the digital resources they offer. In addition, although digital innovation by definition includes a network layer that enables the transmission of signals, users do not seem to consider the network layer when selecting digital resources. Therefore, the network layer seems not to be a crucial argument for users in a non-professional context to select or recombine a digital resource.

Building upon our findings, we derive valuable avenues for future research. Table 4 highlights three key considerations and puts forward questions for future research. 
Table 4. Key Considerations and Future Research

\begin{tabular}{|c|c|}
\hline $\begin{array}{c}\text { Key Considera- } \\
\text { tions }\end{array}$ & Research Questions for Future Research \\
\hline $\begin{array}{l}\text { Distinction between } \\
\text { intra-layer recom- } \\
\text { bination and inter- } \\
\text { layer recombina- } \\
\text { tion. }\end{array}$ & $\begin{array}{l}\text { - Which role does the product-agnostic nature of digital resources play for } \\
\text { users when carrying out either intra-layer or inter-layer recombinations? } \\
\text { Are there generally different motivations to consider intra-layer or inter- } \\
\text { layer recombinations? } \\
\text { - How, if at all, does the distinction between intra-layer and inter-layer re- } \\
\text { combination influence the firm's strategy to appropriate value? }\end{array}$ \\
\hline $\begin{array}{l}\text { Network layer ap- } \\
\text { pears to not be con- } \\
\text { sidered by users } \\
\text { when selecting and } \\
\text { recombining digital } \\
\text { resources. }\end{array}$ & $\begin{array}{l}\text { - Under what circumstances (e.g., privacy concerns), if at all, do users con- } \\
\text { sider the network layer when selecting and recombining digital resources? } \\
\text { - Which role does the network layer play for firms when recombining digi- } \\
\text { tal resources with the aim to produce new, digital value offerings to users? } \\
\text { How can firms leverage the network layer, which appears to not be con- } \\
\text { sidered by users, to communicate value to users and, thereby, channel } \\
\text { value paths through the digital resources offered by them? }\end{array}$ \\
\hline $\begin{array}{l}\text { Influence between } \\
\text { use and design re- } \\
\text { combination ap- } \\
\text { pears not to be con- } \\
\text { sidered by users. }\end{array}$ & $\begin{array}{l}\text { - Under which circumstances, if at all, do users consider their influence on } \\
\text { design recombination and their power to shape digital innovation? } \\
\text { - How can firms promote path channeling by fostering more use recombina- } \\
\text { tion with digital resources they control? } \\
\text { - How can firms develop mechanisms that promote path channeling by al- } \\
\text { lowing users to appropriate a part of the created value? }\end{array}$ \\
\hline
\end{tabular}

To conclude, this paper examines the reasons behind the selection and recombination process carried out by users. Our findings allow us to make three key contributions to extant literature: (1) We underscore the importance to distinguish between intra-layer and inter-layer recombination and uncover different reasons for users to carry out intraor inter-layer recombination. (2) We show that the network layer appears to be invisible to users in a personal context. (3) We outline recommendations and research questions for future research, based on our findings. 


\section{References}

1. Schumpeter, J.A.: The Theory of Economic Development. An Inquiry into Profits, Capital, Credit, Interest, and the Business Cycle. Harvard University Press, Cambridge, Mass (1934)

2. Fleming, L.: Recombinant Uncertainty in Technological Search. Management Science 47, 117-132 (2001)

3. Kogut, B., Zander, U.: Knowledge of the Firm, Combinative Capabilities, and the Replication of Technology. Organization Science 3, 383-397 (1992)

4. Galunic, D.C., Rodan, S.: Resource Recombinations in the Firm. Knowledge Structures and the Potential for Schumpeterian Innovation. SMJ 19, 1193-1201 (1998)

5. Karim, S., Kaul, A.: Structural Recombination and Innovation. Unlocking Intraorganizational Knowledge Synergy Through Structural Change. Organization Science 26, 439-455 (2015)

6. Yoo, Y., Henfridsson, O., Lyytinen, K.: The New Organizing Logic of Digital Innovation. An Agenda for Information Systems Research. ISR 21, 724-735 (2010)

7. Yoo, Y., Boland, R.J., Lyytinen, K., Majchrzak, A.: Organizing for Innovation in the Digitized World. Organization Science 23, 1398-1408 (2012)

8. Henfridsson, O., Mathiassen, L., Svahn, F.: Managing Technological Change in the Digital Age. The Role of Architectural Frames. JIT 29, 27-43 (2014)

9. Sambamurthy, Bharadwaj, Grover: Shaping Agility through Digital Options. Reconceptualizing the Role of Information Technology in Contemporary Firms. MISQ 27, 237 (2003)

10. Lee, J., Berente, N.: Digital Innovation and the Division of Innovative Labor: Digital Controls in the Automotive Industry. Organization Science 23, 14281447 (2012)

11. Henfridsson, O., Nandhakumar, J., Scarbrough, H., Panourgias, N.: Recombination in the Open-ended Value Landscape of Digital Innovation. Information and Organization 28, 89-100 (2018)

12. Nambisan, S., Lyytinen, K., Majchrzak, A., Song, M.: Digital Innovation Management: Reinventing Innovation Management Research in a Digital World. MISQ 41, 223-238 (2017)

13. Lucas, H.C., Goh, J.M.: Disruptive Technology: How Kodak Missed the Digital Photography Revolution. JSIS 18, 46-55 (2009)

14. Yoo, Y.: Computing in Everyday Life. A Call for Research on Experiential Computing. MISQ 34, 213-232 (2010)

15. Kallinikos, J., Aaltonen, A., Marton, A.: The Ambivalent Ontology of Digital Artifacts. MISQ 37, 357-370 (2013)

16. Hund, A., Wagner, H.-T.: Innovation Networks and Digital Innovation. How Organizations Use Innovation Networks in a Digitized Environment. Proceedings of the 14th International Conference on Wirtschaftsinformatik (IS) Siegen, Germany, 1-15 (2019)

17. Lyytinen, K., Yoo, Y., Boland Jr., R.J.: Digital Product Innovation Within Four Classes of Innovation Networks. ISJ 26, 47-75 (2016) 
18. Hund, A., Wagner, H.-T., Gewald, H.: The Impact of Digitization on Contemporary Innovation Management. Proceedings of the 25th Americas Conference on Information Systems (AMCIS) Cancún, Mexico, 1-9 (2019)

19. Hund, A.: Recombination in Times of Pervasive Digitalization: A Review. Proceedings of the 41 st International Conference on Information Systems (ICIS) India, 1-17 (2020)

20. Hund, A., Holotiuk, F., Wagner, H.-T., Beimborn, D.: Knowledge Management in the Digital Era. How Digital Innovation Labs Facilitate Knowledge Recombination. Proceedings of the 27th European Conference on Information Systems (ECIS) Stockholm-Uppsala, Sweden, 1-15 (2019)

21. DeLanda, M.: A new philosophy of society. Assemblage theory and social complexity. Continuum, London (2006)

22. Nambisan, S., Lyytinen, K., Yoo, Y. (eds.): Handbook of digital innovation. Edward Elgar Publishing, Cheltenham, UK, Northampton, MA (2020)

23. Majchrzak, A., Griffith, T.L.: The new wave of digital innovation: the need for a theory of sociotechnical self-orchestration. In: Nambisan, S., Lyytinen, K., Yoo, Y. (eds.) Handbook of digital innovation, pp. 17-40. Edward Elgar Publishing, Cheltenham, UK, Northampton, MA (2020)

24. Monteiro, E.: Reflections on Digital Innovation. Information and Organization 28, 101-103 (2018)

25. Mayring, P.: Qualitative Content Analysis: Theoretical Foundation, Basic Procedures and Software Solution. Klagenfurt (2014)

26. Creswell, J.W., Creswell, J.D.: Research Design. Qualitative, Quantitative, and Mixed Methods Approaches. SAGE, Los Angeles (2018)

27. Davis, F.D., Bagozzi, R.P., Warshaw, P.R.: User Acceptance of Computer Technology: A Comparison of Two Theoretical Models. Management Science 35, 982-1003 (1989)

28. Svahn, F., Mathiassen, L., Lindgren, R., Kane, G.C.: Mastering the Digital Innovation Challenge. MIT Sloan Management Review 58, 14-16 (2017)

29. Ciriello, R.F., Richter, A., Schwabe, G.: The paradoxical effects of digital artefacts on innovation practices. EJIS 28, 149-172 (2019)

30. Carnabuci, G., Operti, E.: Where Do Firms' Recombinant Capabilities Come From? Intraorganizational Networks, Knowledge, and Firms' Ability to Innovate through Technological Recombination. SMJ 34, 1591-1613 (2013)

31. Helfferich, C.: Leitfaden- und Experteninterviews. In: Baur, N., Blasius, J. (eds.) Handbuch Methoden der empirischen Sozialforschung, pp. 669-686. Springer Fachmedien Wiesbaden, Wiesbaden (2019) 